\title{
INASH: Uma Ferramenta de Autoria para Narrativas Interativas Digitais
}

\author{
Vinicius Hartmann Ferreira, Luís Guilherme Eich
}

\author{
Instituto Federal de Educação, Ciência e Tecnologia do Rio Grande do Sul - Campus \\ Feliz \\ Feliz - RS - Brasil \\ vinihfegmail.com, gui.eich@hotmail.com
}

\begin{abstract}
This article presents the INASH tool (Interactive Narratives Shared), which seeks to encourage the practice of reading and writing in students by building interactive narratives. The tool allows the user to create their own narratives, by providing alternative ways for readers, and share them with other users. An experiment with the use of the tool was performed with a technical high school class consists of 24 students. At the end of the experiment the students answered a questionnaire by which it was possible to identify that the tool displays elements that can stimulate students' interest in writing and reading, as the graphical interface construction and its production sharing.
\end{abstract}

Resumo. Este artigo apresenta a ferramenta INASH (Interactive Narratives Shared), que busca estimular a pratica da leitura e da escrita em estudantes através da construção de narrativas interativas. A ferramenta permite ao usuário criar suas próprias narrativas, estipulando caminhos alternativos para os leitores escolherem durante a leitura, $e$ compartilhá-las com os demais usuários. Um experimento com o uso da ferramenta foi realizado com uma turma de ensino médio técnico composta por 24 alunos. Ao final do experimento os alunos responderam a um questionário através do qual foi possível identificar que a ferramenta apresenta elementos que podem estimular o interesse dos alunos pela escrita e pela leitura, como a interface gráfica de construção e o compartilhamento de suas produções.

\section{Introdução}

A escrita e a leitura são habilidades importantes em todas as áreas de conhecimento. Porém, testes internacionais, como o PISA, indicam que o nível de leitura e escrita dos alunos com 15 anos no Brasil está abaixo da média internacional, alcançando pontuação inferior a países da América do Sul como Chile e Uruguai. Além disso, também foi possível constatar através do PISA que os alunos estão lendo menos por prazer, embora aqueles que indicaram ler por prazer tenham obtido melhor desempenho no teste (OECD, 2013).

Aproximar a escrita e a leitura daquilo que atrai os alunos de ensino médio é uma estratégia relevante para estimulá-los a sua prática (Carbonaro et al., 2008). Neste contexto, narrativas interativas surgem como uma possibilidade de relacionar a produção textual e a leitura aos jogos digitais, um tema que desperta o interesse dos adolescentes. As narrativas interativas caracterizam-se por não apresentar uma condução linear da narração, dando ao leitor a possibilidade de fazer escolhas que irão alterar o seu rumo. E é neste ponto que as narrativas interativas apresentam similaridade aos jogos digitais, dando ao leitor a sensação de estar jogando. 
Partindo disto, este artigo apresenta uma ferramenta digital para autoria de narrativas interativas digitais, intitulada INASH (Interactive Narratives Shared), desenvolvida por um aluno de curso técnico em informática integrado ao ensino médio. O artigo está estruturado de forma que na seção 2 são apresentados conceitos fundamentais para a compreensão da importância das TICs no apoio a escrita e a leitura, na seção 3 é apresentada a ferramenta desenvolvida, na seção 4 são apresentados a descrição de um experimento e os resultados obtidos e na seção 5 são explicitadas as conclusões obtidas com o experimento.

\section{As TICs no Apoio a Escrita e a Leitura}

A utilização de novas tecnologias para produção textual, e seu amplo domínio, podem trazer benefícios para um aluno, permitindo que ele consiga compreender como melhorar seu texto. Esta nova forma de desenvolver a produção textual vem alterando a forma como um aluno lê, escreve e compreende um texto. Observa-se isso através da forma como ele agora organiza suas ideias e com a facilidade que encontra para compartilhar suas produções (Cordero et al., 2015).

A partir de trabalhos que envolvem o desenvolvimento ou aplicação de ferramentas digitais como suporte ao letramento ou ao estímulo à escrita (Lysenko e Abrami, 2014; Azeredo e Reategui, 2013; Carbonaro et al., 2008), verifica-se que a utilização de tais recursos nestes processos apresenta resultados positivos, destacando o papel de autor dos alunos. É possível constatar que as ferramentas utilizadas e desenvolvidas variam entre aplicações para Desktop e para a Web e abrangem diferentes contextos, como o ensino ou suporte a prática de escrita em língua nativa ou língua estrangeira.

\section{A Ferramenta INASH}

A ferramenta INASH foi construída como um sistema para a Web, utilizando tecnologias como HTML, PHP, CSS e Javascript, e possui duas modalidades de interação: (i) escrita; e (ii) leitura. $\mathrm{Na}$ modalidade de escrita o usuário pode construir uma narrativa interativa digital utilizando o editor visual (Figura 1) e compartilhá-la com os demais usuários do sistema. Na modalidade de leitura o usuário pode ler as produções dos demais usuários e avaliá-las.

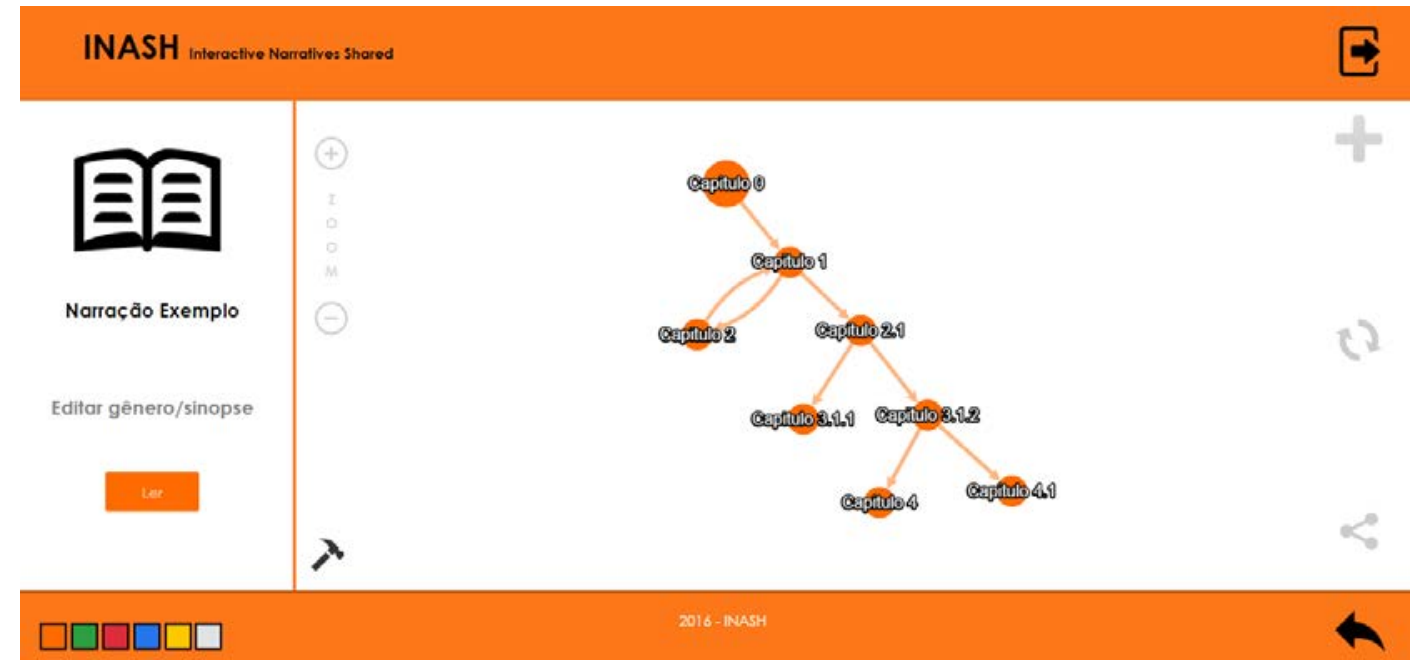

Figura 1. Editor visual da ferramenta INASH. 
O editor visual representa a narrativa na forma de um grafo no qual cada vértice é um capítulo e cada aresta é um caminho possível entre os vértices. A Figura 1 apresenta os recursos disponíveis no editor, sendo eles a inclusão de um novo capítulo, um recurso para zoom no grafo, exclusão de capítulos e compartilhamento da produção. Para editar cada um dos capítulos clica-se na aresta desejada e um editor de textos simples é apresentado para o usuário. As relações entre os capítulos são construídas quando o usuário arrasta uma aresta sobre a outra. Desta forma, a lógica sequencial da narrativa é construída e visualizada na forma de um grafo.

A leitura das narrativas produzidas também é realizada por meio da ferramenta Web. Conforme pode ser visto na Figura 2, a ferramenta apresenta um capítulo escrito pelo usuário e ao final da página as opções que o leitor tem para seguir na história. $\mathrm{Na}$ parte esquerda da tela de leitura é apresentada ao leitor a estrutura dos capítulos da narrativa e a possibilidade de o leitor avaliá-la, indicando se sua opinião sobre a narrativa é positiva ou negativa.

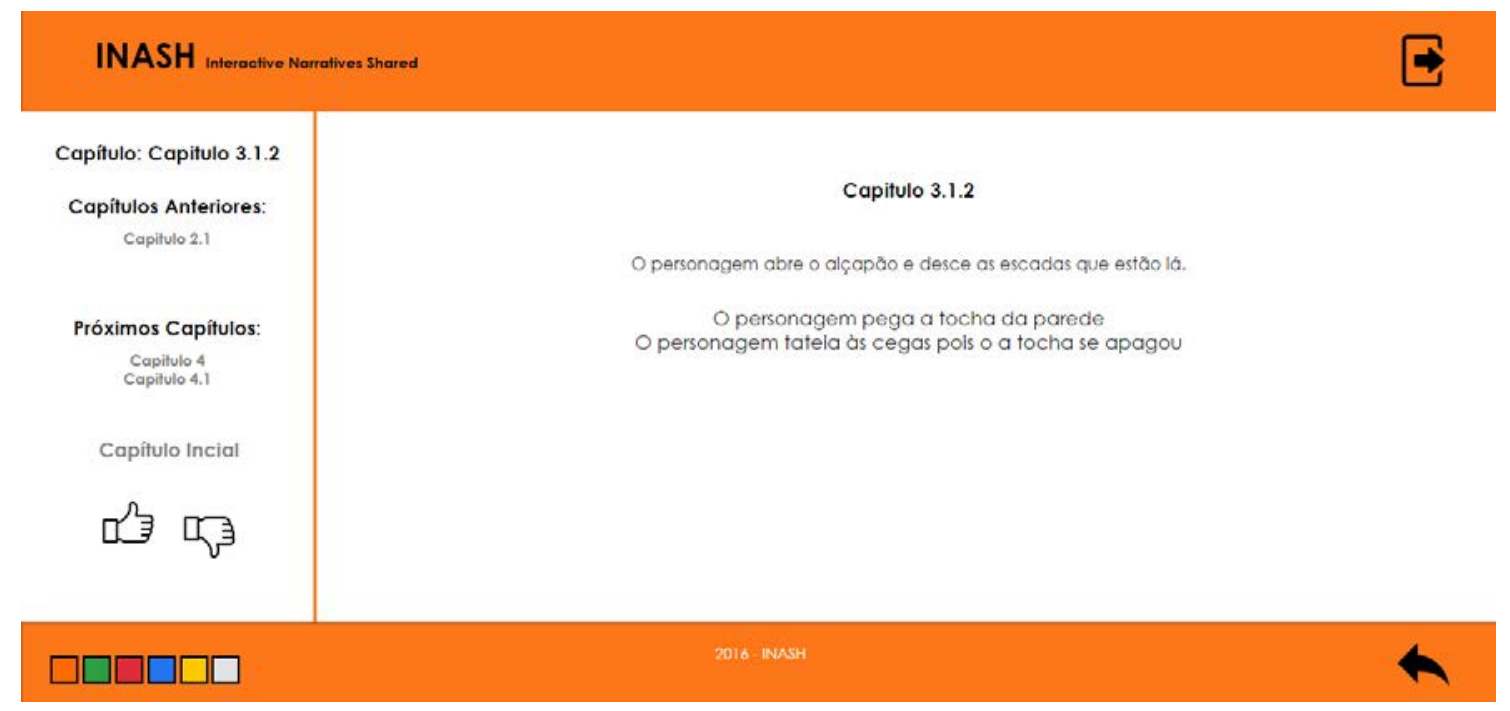

Figura 2. Leitura de uma narrativa na ferramenta INASH.

\section{Experimento e Resultados}

Com o objetivo de avaliar o funcionamento da ferramenta construída e também o seu potencial, mesmo que de forma inicial, no estímulo a prática da escrita e da leitura, um experimento foi realizado com turma de primeiro ano (24 alunos) de um curso técnico integrado ao ensino médio. Neste experimento, que teve a duração de uma aula (45 minutos), os alunos foram conduzidos na utilização da ferramenta para criar uma pequena narração e compartilhá-la e também ler as produções dos colegas e avalia-las. Ao final do experimento os alunos responderam a um questionário que buscava identificar a recepção deles a ferramenta, possíveis dificuldades ou sugestões.

Quanto à escrita, por meio do questionário foi possível identificar que 91,7\% dos alunos consideraram o editor visual como positivo na construção das narrativas. A maioria dos estudantes $(83,3 \%)$ também indicou que a produção através do editor visual é mais atrativa do que a realizada por meios tradicionais e $75 \%$ dos estudantes indicaram que se sentiram mais motivados para produzir um texto por meio do editor visual.

Quanto à leitura, 91,7\% dos estudantes consideraram muito boa a forma como a leitura das narrativas produzidas é realizada na ferramenta. Além disso, apenas um dos estudantes que participou dos testes não leu e não avaliou as produções dos colegas. 
Durante a condução do experimento também foi realizada observação do comportamento dos estudantes. Como não havia um tutorial da ferramenta verificou-se que a etapa na qual eles mais precisaram de auxílio para realizar a atividade foi a de criar relações entre os capítulos arrastando-os uns sobre os outros. Além disso, foram identificados textos explicativos na ferramenta que precisavam de maior clareza. Por fim, ainda que o tempo do experimento tenha sido razoavelmente curto foi possível ver que aqueles alunos que já possuem o hábito de escrever narrativas ou ler livros de ficção se interessaram mais pela ferramenta do que os alunos que não possuem estes hábitos.

\section{Conclusão}

Este artigo apresentou uma ferramenta de autoria para narrativas interativas digitais desenvolvida em um projeto de pesquisa por um aluno de curso técnico em informática integrado ao ensino médio. Além da ferramenta, também foram apresentadas informações sobre a percepção dos estudantes ao usar a ferramenta em um experimento guiado.

Ainda que o intuito do projeto seja estimular a prática da escrita e da leitura em alunos de ensino médio por meio da ferramenta desenvolvida, verificou-se no experimento que este objetivo foi alcançado apenas em alunos que já possuem afinidade com estas atividades. Porém, o fato de aproximar os jogos digitais da produção textual e da leitura e de apresentar um editor visual tende a apresentar melhores resultados quando combinado com práticas pedagógicas utilizadas por mais tempo durante as aulas, conforme relato da professora da turma que acompanhou o experimento.

É válido relatar também que após o experimento e a análise dos resultados obtidos foram realizadas modificações na ferramenta com o intuito de sanar seus problemas técnicos e ela está disponível por meio do endereço http://vhflabs.com.br/inash. Além das correções de código também foi elaborado um vídeo tutorial de uso da ferramenta para sanar as dúvidas dos usuários durante o uso da ferramenta.

\section{Referências}

AZEREDO, D. C.; REATEGUI, E. A construção de narrativas digitais como apoio ao processo de letramento. Novas Tecnologias na Educação, Porto Alegre, v. 11, n. 1, Jul. 2013.

CARBONARO, M.; CUTUMISU, M.; DUFF, H.; GILLIS, S.; ONUCZKO, C.; SIEGEL, J.; SCHAEFFER, J.; SCHUMACHER, A.; SZAFRON, D.; WAUGH, K. Interactive story authoring: a viable form of creative expression for the classroom. Computers and Education, v. 51, n. 1, p. 687-707, 2008.

CORDERO, K.; NUSSBAUM, M.; IBASETA, V.; OTAÍZA, M. J.; GLEISNER, S.; GONZALEZ, S.; RODRÍGUEZ-MONTERO, W.; STRASSER, K.; VERDUGO, R.; UGARTE, A.; CHIUMINATTO, P.; CARLAND, C.. Read Create Share (RCS): a new digital tool for interactive reading and writing. Computers and Education, v. 82, n. 1, p. 486-496, 2015.

LYSENKO, L. V.; ABRAMI, P. C. Promoting reading comprehension with the use of technology. Computers and Education, v. 75, n. 1, p. 162-172, 2014.

OECD. PISA 2012 Results in focus: What 15-year-olds know and what they can do whit that they know, 2013. 